\title{
Examination of IQ in 7 to 14 years old children with sickle cell disease compared with healthy children
}

\author{
Arash Alghasi ${ }^{1 *}$, Zohreh Hassanpour ${ }^{1}$, Mohammad Bahadoram ${ }^{1}$, Somayeh Ashrafi' ${ }^{2}$ Seyed Mohammad Kazem \\ Nourbakhsh ${ }^{3}$
}

${ }^{1}$ Thalassemia and Hemoglobinopathy Research Center, Research Institute of Health, Ahvaz Jundishapur University of Medical Sciences, Ahvaz, Iran

${ }^{2}$ Department of Neurology, Faculty of Medicine, Ahvaz Jundishapur University of Medical Sciences, Ahvaz, Iran

${ }^{3}$ Department of Pediatric Hematology and Oncology, Imam Hospital, Tehran University of Medical Sciences, Tehran, Iran

\section{Correspondence to: \\ Seyed Mohammad Kazem \\ Nourbakhsh; Email address: \\ dr.nourbakhsh2010@gmail.com}

Received: 20 July 2020 Accepted: 10 Oct. 2020 ePublished: 2 Nov. 2020

Keywords: Disease-induced anemia, Healthy children, Sickle cell disease

\begin{abstract}
Introduction: Sickle cell disease (SCD) is a genetic disorder that can be diagnosed by early onset screening tests. In embryos and newborns with sickle cell syndrome, the anatomic development and brain circulation is less than the normal people, and brain circulation plays an important role in brain development.

Objectives: The purpose of this study was to evaluate the level of IQ in children with SCD. Patients and Patients and Methods: The study was a descriptive-epidemiologic. The population of the present study was all children aged 7-14 years old with SCD in Ahvaz. The sample of this study was 50 children with SCD. They were selected from among clients referring to the hepatitis clinic of Shafa hospital in Ahvaz. About 50 healthy children were selected from the first or second-degree family members of the patients with SCD as the control group. The data was collected using Raven's Progressive Matrices (RPM) and demographic information questionnaire.

Results: The mean and standard deviation of IQ scores of the patients with SCD was $94.52 \pm 14.41$, and the mean and standard deviation of IQ scores of healthy subjects was $105.86 \pm 11.38$. The results showed a significant difference between the two groups in terms of IQ score $(P<0.05)$. Moreover, the results showed that IQ level in patients with SCD was significant regarding their place of residence $(P<0.05)$, however IQ level was not significant in patients with SCD regarding gender and race $(P>0.05)$.

Conclusion: The results showed that IQ in children with SCD is lower than that of the healthy subjects. Thus, the present study showed the importance of SCD on children's IQ.
\end{abstract}

\section{Introduction}

Sickle cell disease (SCD) is known as an autosomal recessive disorder occurring due to the inheritance of two HbS genes in children. The disease has a relatively low outbreak and, accordingly, in some populations it has a prevalence of about $1 / 15000(1,2)$. The prevalence of this disease is high in Africa, South America and Central, Caribbean islands, and Mediterranean countries such as Turkey, Italy, India and Saudi Arabia (3). In Iran, the prevalence of this disease has been reported to be more in southern provinces like Sistan and Baluchestan, Hormozgan, Bushehr, Fars, and especially Khuzestan, but it is seen sporadically in some areas of northern Iran as well. According to the latest statistics, there are about 500 patients with SCD in Khuzestan (4). Patients with SCD face many complications during their life, such as anemia, sickle cell crises (pain crisis, aplastic crisis and detachment crisis), acute chest syndrome, pulmonary hypertension,

\section{Key point}

Sickle cell disease (SCD) is a group of inherited red blood cell disorders that affects hemoglobin. In this descriptive-epidemiologic study, IQ in children with SCD was lower than of the healthy subjects. IQ level was not significant in patients with SCD regarding gender and race.

spleen infarction, pulmonary infections, stroke, renal failure, jaundice, hepatomegaly, skin ulcers, retinal detachment, and priapism (5). The presence of a disruption in the hemoglobin wall and its becoming sickleshaped lead to fragility of the red blood cells and subsequently attachment of these cells to each other and obstruction of the vessel, and ultimately chronic tissue hypoxia in terms of mechanism and physiopathology $(6,7)$. Disrupted blood supply processes in SCD patients leads to infectious diseases, sepsis, and cerebrovascular accident (CVA) as the most common morbidity in the disease

Copyright (C) 2020 The Author(s); Published by Society of Diabetic Nephropathy Prevention. This is an open-access article distributed under the terms of the Creative Commons Attribution License (http://creativecommons.org/licenses/by/4.0), which permits unrestricted use, distribution, and reproduction in any medium, provided the original work is properly cited. 
(8). Chronic anemia through oxygen depletion affects cognitive performance directly (9). It has been suggested that chronic anemia and reduction in oxygen supply to the brain are associated with this decrease in cognitive function (10). Moreover, psychological variables (such as caring stress and poor nutrition) are also known as risk factors for poor cognitive function in children with SCD $(11,12)$. The most common complications of SCD in the nervous system are neurological complications, and neurological complications are the most important consequences of the disease, with one-third of the patients with the disease experiencing neurological complications (12-14). Studies suggest that children with a sickle-cell anemia experience a certain disability with a number of cognitive skills, such as attention, concentration, and decoding (15) and social functions (9). This impairment is seen, especially in crystalline intelligence, processing speed, and short-term memory (16). The most common area of injury in patients with SCD is brain frontal lobe (17). Damage in this area decreases the effectiveness of repetition of verbal information in working memory, causes problems in manipulating verbal information in working memory, and poor verbal information retrieval in the test of memory reminder $(18,19)$.

\section{Objectives}

Studies also show that early decline in cognitive function between 12 and 24 months is seen with the lack of attention and performance in preschool children (16). Moreover, studies have shown that in embryos and infants suffering from SCD, anatomical development and brain circulation are less than the normal people; therefore, this study seeks to answer the question of whether there are differences among children with SCD and normal children regarding IQ (20-22).

\section{Patients and Methods}

\section{Study design}

The study was a descriptive-epidemiologic. The population of the present study was all children aged 7-14 years old with SCD in Ahvaz. The sample of this study was 50 children with SCD. They were selected from among clients referring to the hepatitis clinic of Shafa hospital in Ahvaz. Around 50 healthy children were selected from the first or second-degree family members of the patients with SCD as the control group. Inclusion criteria were oral and written consent to enter the study, the absence of a disease causing cognitive impairment in the past or now, the absence of chronic diseases except the disease studied, the age 7-14 years, the presence of heterozygote and homozygous sickle cells, the absence of any neurological disorder (except silent CVA) and the absence of seizure and admission during the study (patients at the time of were symptom-free). In addition, in the case of patients' lack of consent, the presence of chronic concomitant diseases, the presence of crisis SCD in patients and the presence of apparent neurological disorders or simultaneous chronic illness, the subjects were excluded. Research data was collected by Raven's Advanced Progressive Matrices ${ }^{\mathrm{TM}}$ (APM) and demographic information questionnaire (23). At the beginning of the study, the informed consent was taken and the whole process of study was explained to the subjects.

\section{Ethical issues}

This study was conducted in accordance with the principles of the Declaration of Helsinki. This research was part of a pediatric residency thesis approved of Zohreh Hassanpour which was financially supported by a grant from Ahvaz Jundishapur University of Medical Sciences, Ahvaz, Iran (Grant\# TH96/7).

\section{Data analysis}

The data was collected using Raven's Progressive Matrices (RPM) and demographic information questionnaire. Comparison between SCD subjects and age-matched and gender-matched healthy subjects was made using the independent t-test. Data management and statistical analysis were performed using the SPSS Statistics software (version 25), while $P$ value less than 0.05 was considered as statistically significant.

\section{Results}

The study examined 50 children with SCD-24 (48\%) boys and (52\%) girls and 50 healthy children, all of whom were girls, and evaluated for IQ. The mean and standard deviation of the age of the patients with anemia was 10.23 \pm 1.23 years and the mean and standard deviation of the age of healthy subjects was $10.94 \pm 1.17$ years. Around $90 \%$ of the patients with SCD were Arabs and 10\% were Fars. Moreover, $78 \%$ of them were living in city areas and 22\% in rural areas. In the healthy subjects, $16 \%$ were Arab and $84 \%$ Fars; $98 \%$ were in the city and $2 \%$ in the village.

The results showed that the mean and standard deviation of IQ scores of the patients with SCD were 94.52 \pm 14.41 and the mean and standard deviation of IQ scores of healthy subjects was $105.86 \pm 11.38$. Here, healthy subjects had significantly higher IQ than patients $(P<0.05$; Table 1).

The results showed no significant difference between the patients with SCD regarding gender and ethnicity $(P>0.05 ;$ Table 2). Furthermore, the results showed a significant difference between patients with SCD based on their place of residence. Regarding the difference in mean, one can state that the IQ score of patients with SCD living in the city is higher than the IQ score of SCD patients

Table 1. The mean and standard deviation of IQ scores of the samples

\begin{tabular}{lllll}
\hline Group & Number & Mean \pm SD & Minimum & Maximum \\
\hline SCD & 50 & $94.52 \pm 14.41$ & 67 & 157 \\
Healthy & 50 & $105.86 \pm 11.38$ & 66 & 130 \\
\hline
\end{tabular}


Table 2. The level of IQ in patients with SCD regarding gender, place of residence

\begin{tabular}{llllll}
\hline Parameters & Number & Mean \pm SD & Min. & Max. & $P$ value \\
\hline Gender & & & & & 0.35 \\
Boy & 24 & $92.54 \pm 10.23$ & 67 & 123 & \\
Girl & 26 & $96.34 \pm 14.12$ & 66 & 157 & \\
Race & & & & & 0.93 \\
Arab & 45 & $94.46 \pm 14.53$ & 67 & 157 & \\
Persian & 5 & $95.00 \pm 14.86$ & 82 & 120 & \\
Location & & & & & 0.02 \\
Urban & 39 & $95.00 \pm 14.63$ & 77 & 157 & \\
Rural & 11 & $85.72 \pm 9.70$ & 67 & 100 & \\
\hline
\end{tabular}

living in rural areas $(P<0.05$; Table 2).

\section{Discussion}

The purpose of this study was to examine and compare the IQ in 7-14 y old children with SCD compared to healthy children. The results showed that the mean and standard deviation of IQ scores of the patients with SCD was 94.52 \pm 14.41 and the mean and standard deviation of IQ scores of healthy subjects was $105.86 \pm 11.36$. The results showed that the IQ score of these children was moderate and their IQ score was lower than that of the normal healthy children. This difference was statistically significant. This was consistent with research that evaluated and compared the IQ scores in patients with SCD and healthy subjects. Schatz and Roberts showed a significant difference between the IQ score of children with SCD and normal children, with SCD children having 3-4 units lower IQ (9). Kawadler et al in a review study examined the IQ of children with SCD. Their results showed that the IQ in the affected children was significantly lower than the control group, and biological, socioeconomic, and environmental factors could play an important role in creating these conditions (24). In addition, Oluwole et al examined the cognitive function of children with SCD. In this study, 56 patient's children were compared with 44 healthy ones. The researchers concluded that the cognitive function of children with SCD is lower than that of the healthy children and cognitive function is correlated with anthropomorphic, demographic and social factors (25). In explaining these results and the consistency of the studies, it should be noted that the most common area of injury in patients with SCD is the brain frontal lobe (17). Working memory, inhibition and performance in some problem solving/ planning tests depend upon the function of the frontal lobe of the brain (26). Damage in this area causes children with anemia to develop a specific disability with a number of cognitive skills, including attention, focus and decoding, and executive functions $(9,15)$. On the one hand, "executive functions" is an umbrella term referring to cognitive processes that provide directional behavior in achieving the desired goal. The components of executive functions generally are planning, inhibition control, and the receipt and maintenance of cognitive information in a desirable way (27). Researchers believe that the three components of inhibition, working memory and planning are the main components of executive action $(28,29)$. Attention, focus, decoding, and executive functions are among the success factors in intelligence tests, so these children get lower scores in IQ tests. In general, the factors that affect the development of the brain during infancy and fetal development can directly affect people's intelligence, so different studies have examined brain development from a variety of aspects. Rushton examined the size of the brain of 5000 babies from birth to age seven and showed that children with larger head circumference had higher IQs (30). Moreover, Steen et al examined 27 children with SCD showing that the volumetric growth of cerebrospinal fluid in children with SCD is delayed compared to healthy people, which may lead to brain-neurological complications in these patients, which itself can justify a lower IQ of these patients than normal people (10). On the other hand, the lack of appropriate blood supply in these individuals may cause hypoxia and brain damageas a hypoxia-sensitive tissue-during and after birth. This could cause the low IQ of these children compared to healthy children (31). The results showed no significant difference between children with SCD regarding gender. This was consistent with the study by Rahmani. He found no significant difference between boys' and girls' IQ scores in this test (32). However, the results of the present study were inconsistent with the study by Lynn et al (33-35). In the meta-analysis by Lynn et al, the mean difference in intelligence in males and females was approximately 4.7 points in the IQ scores (33). Abad et al also obtained a superiority of 4.03 points of intelligence among men $(36,37)$. Colom et al reported a superiority of 4.3 IQ score in men (34). Moreover, Bennett showed an average male superiority of 6.4 points for IQ score Concerning the inconsistency of the results of previous studies with the results of this research, it is necessary to note that none of the researchers has stated anything about the significance of these differences, and in this connection it cannot be said whether these differences are significant or not. Second, in the studies mentioned, the difference in raw grades has been mentioned that in the expression of IQ, the raw score should be calculated according to age. The results showed a significant difference between children with SCD based on their place of residence and urban children have higher intelligence. These results are consistent with Bagheri et al (38). In a study to examine the intelligence status of patients with congenital Candida defects, they showed that the urban intelligence score was significantly higher than that of the rural population. Among the possible causes of this issue, one can refer to the wider range of education in urban children.

\section{Conclusion}

The results showed no significant differences between 
children with SCD regarding ethnicity. This study was consistent with the study by Raven and Court. Raven test is a culture-specific test; thereby, it is not expected to use this tool to differentiate the intelligence of individuals of different ethnic backgrounds. Raven and Court et al stated that the test is appropriate in terms of culture and minimizes the effect of the variance obtained by ethnicity and socioeconomic status (39). One of the limitations is the limitations of society, which should be considered in determining the results of this study to patients with anemia in other provinces and cities. Regarding the results of this study and the effect of SCD on children's intelligence, it is suggested that in future studies, intervention and education should be done on patients with SCD and the effect of these educational programs on cognitive abilities. Moreover, it is recommended that in future studies, intelligence tests, evaluating verbal and functional intelligence separately, such as Wechsler test.

\section{Limitations of the study}

Sample size of this study was low. The scientific literature is limited and inconsistent.

\section{Authors' contribution}

$\mathrm{ZH}, \mathrm{SA}$ and $M B$ were the principal investigators of the study. $\mathrm{ZH}$, $A A, S A$, and $M B$ were included in preparing the concept and design. $A A$ and $M B$ revised the manuscript and critically evaluated the intellectual contents. All authors participated in preparing the final draft of the manuscript, revised the manuscript and critically evaluated the intellectual contents. All authors have read and approved the content of the manuscript and confirmed the accuracy or integrity of any part of the work.

Conflicts of interest

The authors declare that they have no competing interests.

Ethical considerations

Ethical issues (including plagiarism, data fabrication, double publication) have been completely observed by the authors.

\section{Funding/Support}

This study was financially supported by Ahvaz Jundishapur University of Medical Sciences (Grant \# TH96/7).

\section{References}

1. Adams RJ, Aaslid R, El Gammal T, Nichols FT, McKie V. Detection of cerebral vasculopathy in sickle cell disease using transcranial Doppler ultrasonography and magnetic resonance imaging. Case report. Stroke 1988;19:518-20. doi: 10.1161/01.STR.19.4.518.

2. Adams R, McKie V, Carl E, Nichols FT, Perry R, Brock K. Longterm stroke risk in children with sickle cell disease screened with transcranial Doppler. Ann Neurol 1997; 42: 699-704.doi: 10.1002/ana.410420505

3. Chakravorty S, Williams TN. Sickle cell disease: a neglected chronic disease of increasing global health importance. Arch Dis Child. 2015;100:48-53. doi: 10.1136/ archdischild-2013-303773.

4. Rahimi Z, Vaisi-Raygani A, Nagel RL, Muniz A. Thrombophilic mutations among Southern Iranian patients with sickle cell disease: high prevalence of factor $\mathrm{V}$ Leiden. J Thrombosis Thrombolysis 2008;25:288-292. doi: 10.1007/s11239-007- 0069-x.

5. Majumdar S. The adolescent with sickle cell disease. Adolesc Med State Art Rev. 2013;24:295-306.

6. Ware RE, Zimmerman SA, Sylvestre PB, Mortier NA, Davis JS, Treem WR. Prevention of secondary stroke and resolution of transfusional iron overload in children with sickle cell anemia using hydroxyurea and phlebotomy. J Pediatr 2004;145:346352. doi: 10.1016/j.jpeds.2004.04.058.

7. Kinney TR, Sleeper LA, Wang WC, Zimmerman RA, Pegelow $\mathrm{CH}$, Ohene-Frempong K. Silent cerebral infarcts in sickle cell anemia: a risk factor analysis. Pediatrics. 1999;103:640-5. doi: 10.1542/peds.103.3.640.

8. Berkelhammer LD, Williamson AL, Sanford SD, Dirksen CL, Sharp WG, Margulies AS. Neurocognitive sequelae of pediatric sickle cell disease: a review of the literature. Child Neuropsychol 2007;13:120-131. doi: 10.1080/09297040600800956.

9. Schatz J, Roberts CW. Neurobehavioral impact of sickle cell disease in early childhood. J Int Neuropsychol Soc. 2007;13: 933-43. doi: 10.1017/S1355617707071196.

10. Steen RG, Miles MA, Helton KJ, Strawn S, Wang W, Xiong $X$. Cognitive impairment in children with hemoglobin SS sickle cell disease: relationship to MR imaging findings and hematocrit. Am J Neuroradiol. 2003;24:382-389.

11. Tarazi RA, Grant ML, Ely E, Barakat LP. Neuropsychological functioning in preschool-age children with sickle cell disease: the role of illness-related and psychosocial factors. Child Neuropsychol. 2007;13:155-72. doi: 10.1080/09297040600611312.

12. Baldeweg T, Hogan AM, Saunders DE, Telfer P, Gadian DG, Vargha-Khadem F. Detecting white matter injury in sickle cell disease using voxel-based morphometry. Ann Neurol. 2006; 59:662-672. doi: 10.1002/ana.20790

13. McClellan CB, Schatz J, Sanchez C, Roberts CW. Validity of the pediatric quality of life inventory for youth with sickle cell disease. J Pediatr Psychol 2008;33:1153-62. doi: 10.1093/ jpepsy/jsn036

14. Kral MC, Brown RT, Hynd GW. Neuropsychological aspects of pediatric sickle cell disease. Neuropsychol Rev. 2001;11: 179-196. doi: 10.1023/A:1012901124088.

15. Brown RT, Armstrong FD, Eckman JR. Neurocognitive aspects of pediatric sickle cell disease. J Learning Disabilities. 1993; 26:33-45. doi: 10.1177/002221949302600104.

16. Schatz J, Finke R, Roberts CW. Interactions of biomedical and environmental risk factors for cognitive development: a preliminary study of sickle cell disease. J Developmental Behavioral Pediatr. 2004;25:303-310. doi: 10.1097/00004703200410000-00001.

17. Brown RT, Davis PC, Lambert R, Hsu L, Hopkins K, Eckman J. Neurocognitive functioning and magnetic resonance imaging in children with sickle cell disease. J Pediatr Psychol. 2000;25: 503-13. doi: 10.1093/jpepsy/25.7.503

18. Brandling-Bennett EM, White DA, Armstrong MM, Christ SE, DeBaun M. Patterns of verbal long-term and working memory performance reveal deficits in strategic processing in children with frontal infarcts related to sickle cell disease. Developmental Neuropsychol 2003;24:423-34. doi: 10.1207/ S15326942DN2401_01.

19. White DA, Salorio CF, Schatz J, DeBaun M. Preliminary study of working memory in children with stroke related to sickle cell disease. J Clin Exp Neuropsychol. 2000;22:257-264. doi: 10.1076/1380-3395(200004)22:2;1-1;FT257

20. Banafshe HR, Hajhashemi V, Minaiyan M, Mesdaghinia A, Abed A. Antinociceptive effects of maprotiline in a rat model of peripheral neuropathic pain: possible involvement of opioid system. Iranian J Basic Med Sci. 2015;18:752. doi: 10.1016/ S0924-977X(15)30280-7. 
21. Steen RG, Hunte M, Traipe E, Hurh P, Wu S, Bilaniuk L. Brain T1 in young children with sickle cell disease: evidence of early abnormalities in brain development. Magnetic Resonance Imaging. 2004;22:299-306. doi: 10.1016/j.mri.2004.01.022.

22. Steen RG, Emudianughe T, Hunte M, Glass J, Wu S, Xiong X. Brain volume in pediatric patients with sickle cell disease: evidence of volumetric growth delay? Am J Neuroradiol. 2005; 26:455-462.

23. Stough C, Mangan G, Bates T, Pellett O. Smoking and raven IQ. Psychopharmacology. 1994;116:382-384. doi: 10.1007/ BF02245346.

24. Kawadler JM, Clayden JD, Clark CA, Kirkham FJ. Intelligence quotient in paediatric sickle cell disease: a systematic review and meta-analysis. Developmental Med Child Neurol. 2016;58: 672-679. doi: 10.1111/dmcn.13113.

25. Oluwole OB, Noll RB, Winger DG, Akinyanju O, Novelli EM. Cognitive functioning in children from Nigeria with sickle cell anemia. Pediatr Blood Cancer. 2016;63:1990-1997. doi: 10.1002/pbc. 26126

26. Zook NA, Davalos DB, DeLosh EL, Davis HP. Working memory, inhibition, and fluid intelligence as predictors of performance on Tower of Hanoi and London tasks. Brain Cognition. 2004; 56:286-292. doi: 10.1016/j.bandc.2004.07.003.

27. Morgan AB, Lilienfeld SO. A meta-analytic review of the relation between antisocial behavior and neuropsychological measures of executive function. Clin Psychol Rev. 2000; 20: 113-36. doi: 10.1016/S0272-7358(98)00096-8.

28. Faraone SV, Doyle AE. Attention-deficit/hyperactivity disorder. In: Emery and Rimoin's Principles and Practice of Medical Genetics. Elsevier; 2013. p. 1-8. doi: 10.1016/B978-0-12383834-6.00114-2.

29. Denckla MB. Biological correlates of learning and attention: What is relevant to learning disability and attention-deficit hyperactivity disorder? J Dev Behav Pediatr. 1996 Apr;17:1149. doi: 10.1097/00004703-199604000-00011.
30. Rushton JP. Cranial size and IQ in Asian Americans from birth to age seven. Intelligence 1997;25:7-20. doi: 10.1016/S01602896(97)90004-0.

31. Naeye RL, Peters E. Antenatal hypoxia and low IQ values. Alcoholism 987;141:50-4. doi: 10.1001/ archpedi.1987.04460010050022.

32. Rahmani J. Reliability, validity and standadization of Raven progressive matrics test in Khorasgan Azad University. Knowledge Res Pstchol. 2007;61:561-571.

33. Lynn R, Allik J, Irwing P. Sex differences on three factors identified in Raven's Standard Progressive Matrices. Intelligence 2004;32:411-424. doi: 10.1016/j.intell.2004.06.007.

34. Colom R, Escorial S, Rebollo I. Sex differences on the progressive matrices are influenced by sex differences on spatial ability. Pers Individ Dif. 2004; 37: 1289-93. doi: 10.1016/j.paid.2003.12.014.

35. Mackintosh NJ, Bennett E. What do Raven's matrices measure? An analysis in terms of sex differences. Intelligence. 2005;33: 663-674. doi: 10.1016/j.intell.2005.03.004.

36. Abad FJ, Colom R, Rebollo I, Escorial S. Sex differential item functioning in the Raven's Advanced progressive matrices: Evidence for bias. Pers Individ Dif. 2004;36:1459-70. doi: 10.1016/S0191-8869(03)00241-1

37. Raven J. Manual for Raven's progressive matrices and vocabulary scales. Research supplement no. 3: A compendium of international and North American normative and validity studies together with a review of the use of the RPM in neuropsychological assessment by Court. San Antonio, TX: The Psychological Corporation; 2000.

38. Bagheri A, Fallahi MR, Tamannaifard S, Vajebmonfared S, Zonozian S. Intelligence Quotient (IQ) in Congenital Strabismus. J Ophthalmic Vis Res. 2013;8:139-46.

39. Raven JC, Court JH. Manual for Raven progressive matrices and vocabulary scales. Psychol Corporation; 1993. 